\title{
7. Taking voice and taking sides: the role of social media commenting in solidarity contestation
}

\author{
Hans-Jörg Trenz, Verena K. Brändle, \\ Manlio Cinalli and Olga Eisele
}

\subsection{INTRODUCTION}

New media forms and social media are increasingly used by citizens to engage with and debate the boundaries of political community and solidarity. Yet, the effects of fragmentation or inclusiveness on the public sphere are seen as ambivalent. In the literature, the destabilisation effects of social media on existing communities or publics are emphasised. In particular, social media and news commenting sites are often held responsible for the spread of hate speech and uncivic culture towards fellow citizens (Gerhards and Schafer, 2010; Michailidou et al., 2014; Rasmussen, 2014). Others, however, emphasise the new opportunities provided by social media as a stimulus for agenda-setting, more inclusive deliberation, identity-building, and therefore also solidarity. Political debates are more civic, global, inclusive and accessible, and empower disadvantaged groups and pluralise the public sphere in various ways (Dahlgren, 2013; Rauchfleisch and Kovic, 2016). An uncivic online sphere, on the other hand, would be a major threat to established solidarity relationships.

The potential both to erode and to empower solidarity bonds across social, political and national boundaries establishes online and social media as networks or platforms for the contestation of solidarity. What these new ways for solidarity contestation have in common is that they engage users with media content that conveys information or messages about the needs of other people. Through the confrontation with such content, social media users become witnesses of instances of distant suffering by others. Such witnessing creates a situation of moral spectatorship (Boltanski, 1999; Silverstone, 2006). Social media moral spectatorship can consequently build more immediate relationships to objects of suffering while, at the same time, activating critical capacities of online citizen-users 
(Mortensen and Trenz, 2016). The witnessing of human suffering through the media is, on the one hand, paired with the expression of strong emotions such as pity, indignation or hate. On the other hand, it raises moral demands that can motivate and encourage media users to commit and to group each other around a cause. In contrast to the more passive reception of political news through legacy media, social media witnessing of controversial, shocking or concerning news content can easily become more personal and committing (Chouliaraki, 2013; Mortensen and Trenz, 2016). Forms of moral spectatorship can, for instance, create new opportunities for global solidarity mobilisation through visuals that are shared on social media platforms and translated into political speech which claims solidarity with victims in other parts of the world and ascribes responsibility (Chouliaraki, 2013; Chouliaraki and Stolic, 2017). In contrast, it can also fuel perceptions of stigmatisation, threat or hate towards minority groups - also in combination with circulated unauthentic material (Georgiou and Zaborowski, 2017). In other words, they mobilise emotional debates. By expressing this commitment through posting or liking, for example, the expression of emotions is translated into forms of political speech. Such political expressions of emotions, whether or not the concerned person or group deserves solidarity in a controversial way, ascribe political responsibility.

In the overall context of this book, we consider social media platforms as particularly promising arenas for citizens' contestation of solidarity. In this chapter, we further extend our view on solidarity contestation through the media from Chapter 6 with an interest in political discourse (Cinalli and Giugni 2013 and 2016), by focusing on bottom-up dynamics of solidarity contestation through social media by citizen-users. We focus our analysis of this type of user-driven bottom-up contestation on the case of the 'refugee crisis' of September 2015. That month was marked by a series of dramatic events that brought the 'refugee crisis' to the attention of mass audiences. In particular, the highly emotive images of Alan Kurdi, the drowned boy from Syria found at the beach in Turkey in September 2015 were widely shared through social media and triggered a wave of solidarity mobilisation (Thomas et al., 2018). Other instances of moral spectatorship generated risk perceptions, threats and rejection of solidarity, as for example, in the case of the New Year's Eve 2015/16 sexual assaults and muggings in Cologne. We thus expect the need for (trans)national solidarity with migrants to be discussed controversially on social media in direct response to news coverage delivered by professional journalists.

Given the complementary nature of this chapter to the claims-making analysis of mainstream media coverage (see Cinalli et al., Chapter 6 in this volume), we selected Facebook user comments that were posted in 
response to news articles on mainstream newspapers' Facebook pages. This suited our aim of collecting data on the more hidden side of the public sphere. While our claims-making analysis in Chapter 6 allowed us to map the official voices that were capable of leading politics (Freeman, 1995, 1998), the online commenting analysis in this chapter collects the various informal ways users as news readers on social media seize the chance to express emotions and translate them into political speech from the bottom up. The following analysis thus adds to an understanding of solidarity contestation from the bottom up, considering users' Facebook comments below posted news articles as arenas for direct intervention with political discourse.

Bottom-up mobilisation of solidarity is commonly analysed in terms of initiatives by civil society activists, affected citizens, communities and grassroots movements to provide support to vulnerable groups of the population (see Kousis et al., Chapter 3 in this volume). An investigation of bottom-up contestation about solidarity on social media sheds light on a particular arena where citizens form their opinions and commit to social and political norms or values, as in our case solidarity. Our investigation emphasises hereby, first, the ways in which citizens express their opinions and emotions and how they make use of some of the affordances offered by social media. We wish to address the question to what extent emotional expressions translate into moral commitment and political speech, that is, the question of the civic- or uncivicness of solidarity contestation. Second, we focus on citizens' moral commitments and political speech themselves, that is, the question of to what extent they reject or support solidarity in these instances.

\subsubsection{Civic and Uncivic Elements of Online Solidarity Contestation}

As a response to being confronted with the news coverage of the 'refugee crisis', commenting social media users enter into some sort of collective, interpretative work. They produce text in the form of comments that relate to news media content in specific ways, e.g. by interpreting the evidence presented in the newspaper articles, by supporting or rejecting claims raised by politicians in the news media or by ascribing political responsibility and reflecting on political consequences. It is, of course, an exaggeration to say that these interpretations unfold in a completely autonomous way. Structures of meaning in user debates remain embedded and are influenced by the frames of interpretation used by political actors in the mainstream media (Galpin and Trenz, 2019) but in addition to journalists, intellectuals and political actors as claimants, the users now contribute in significant ways to the generation of public discourse. To perform this 
interpretative work, social media users need to relate to each other and engage in an exchange of arguments. They need to come up with their own justifications as to why solidarity towards refugees is accepted or rejected.

The manners in which such an exchange of arguments is organised varies, however, in important ways. In the following, we wish to distinguish conceptually between two alternative scenarios of an online civic sphere and an online uncivic sphere of solidarity contestation. According to the first scenario, news readers' commenting practices on social media are part of an online civic sphere that enriches the traditional top-down ways of political communication by facilitating horizontal exchanges among citizens, making the media voice more plural and participatory, thus facilitating a more inclusive sphere for the formation of public opinion (Dahlgren, 2013). Commenters on online platforms can be characterised as more active users who consider themselves as people with a relevant voice to be heard (Coleman, 2013: 219). In this way, Facebook news sites offer platforms for these people to engage in the bigger debates, to respond to the claims in the posts curated by the newspapers and, by this, to take voice.

This hypothetical scenario of an online civic sphere can be validated if commenting practices meet the following three criteria. First, we would expect online users to be responsive to news content and to claims raised in the news media. Second, we would expect them to relate directly to refugees as objects of solidarity and to critically judge whether or not solidarity should be granted to them. And third, we would expect users to seek political influence, i.e. to translate informal opinion-making into formal political action. Taking voice through social media commenting should be paired with demands for collective action: 'we shall', 'let's do'. Such calls for actions would typically expand existing bonds of solidarity towards refugees, either by reference to emotions such as pity or by references to universal principles supporting a notion of transnational solidarity. Users would motivate and encourage each other to swing to commitment and to group each other around a cause. As such, they would become secondary definers of the 'refugee crisis' because they would not simply accept or reject claims raised in the media, but also give witness testimony, engage in their own collective practice of interpretation of the situation and take sides on the question of refugee solidarity.

At the same time, online participatory news formats and, in particular, the evolving forms of user commenting on social media and online news sites have become the object of a harsh normative critique (Gerbaudo, 2014; Krämer, 2017). According to our second scenario - the uncivic sphere - online publics would be non-responsive and marginal and overall suffer from deficits of publicity. The online media would engage selected 
citizens, but these debates would remain detached from formal, decisionmaking contexts and would have minimal impact on political outcomes or public opinion in general (Givskov and Trenz, 2014). Considering the general relationship between news content and commenting on Facebook, the online publics would be fragmented into different opinion bubbles, closed communities, where users mainly exchange opinions among the like-minded (Sunstein, 2009; Rasmussen, 2014). Online fragmentation would further affect users' capacities to express informed opinions or to defend values of social justice and solidarity. Closed within their bubbles, online users would position themselves in increasingly polarised ways. Such a polarised constellation of online discourse would be paired with increasing distrust and enmity between the opposing camps who would engage primarily in an exclusive and non-solidaristic rhetoric against their political opponent or against migrants as undeserving outsiders. There would be, in other words, a general tendency in online users to adopt what, in line with Benjamin Moffitt (2016), can be called a populist style in challenging the performance of democratic (representative) politics and to display and amplify primarily positions taken by populist parties in an electoral contest. The online uncivic sphere would in this sense unfold through a populist style of user debates, which would be exclusive and anti-solidaristic against either a political opponent or people in need. In terms of solidarity contestation, we would expect online publics to voice their discontent with established representative politics, to restrict rather than expand solidarity relationships and to target political enemies or refugees in an exclusive way, i.e. as undeserving of solidarity.

\subsubsection{Witnessing Human Suffering: From a Politics of Fear to a Politics of Pity}

An important element of the media story of a humanitarian crisis consists of the expression of emotions such as sympathy or antipathy towards refugees for the purpose of political mobilisation (Chouliaraki, 2013). One (and possibly the most frequent) case for the use of emotions in media discourse on migration was the evocation of fear (Wodak, 2015). A politics of fear can be distinguished as a style of political mobilisation that portrays refugees in the media as threats to be excluded from the solidarity community. In line with such a politics of fear, media coverage builds often on fear-appealing metaphors such as flood, swarms or marauders, or on suffixes such as unwanted, irregular or illegal. Another (and possibly more exceptional) case for the use of emotions in media discourse on the humanitarian crisis is what Boltanski (1999) calls a politics of pity. Pity, which is to be defined as an emotional reaction to the witnessing of human 
suffering, can be considered as an important element in the mobilisation of solidarity in the way it allows for rapid changes of opinion from indifference or even antipathy towards the object of solidarity to attention and personal emotional engagement (to be followed by possible forms of individual or collective support action). In the case of the 'refugee crisis', for instance, one example of the solidarity effects of such a politics of pity would be the so-called welcoming culture that triggered spontaneous reactions of assistance either in the form of direct aid or of financial assistance. Hospitality and empathy towards refugees were motivated here by mediated images of human suffering (such as the image of the drowned boy, Aylan Kurdi, on the Turkish beach), which contributed to rapid shifts in opinion in reception countries and to considerable levels of political mobilisation (Mortensen and Trenz, 2016; della Porta, 2018).

A focus on refugees and asylum seekers as a particular target group of bottom-up solidarity contestation is particularly interesting because the case of solidarity with refugees and asylum seekers has divided public opinion all over Europe with advocates of human rights and open borders opposing supporters of exclusive, nationalist welfare (della Porta, 2018). Online commenting as a form of bottom-up mobilisation could thus take shape either as a politics of fear or a politics of pity. We expect that the social media community of news readers is divided on these issues and that bottom-up contestation of refugee solidarity is triggered by particular events and their interpretation in the media, such as the humanitarian disasters at Europe's external borders that unfolded during the months of 2015/16 (Triandafyllidou, 2018). The dramatic events which were brought into focus by the so-called 'refugee crisis' of September 2015 are particularly interesting because they were staged in many countries as a direct confrontation between citizens and refugees (Thomas et al., 2018). It is therefore all the more interesting to zoom in on solidarity contestation unfolding on Facebook at the peak of a heated debate, when media claimsmaking was most intensive.

We conducted a comparative analysis of online commenting on Facebook news sites in order to assess the political expressions of selected citizen-users who decided to position themselves in debates about refugees. In particular, we were interested in the civic and uncivic elements of online user commenting in response to news. This includes the question whether social media news sites, in addition to sharing information, also offer an opportunity for citizens to take voice or take sides with the cause of refugee solidarity. We expect, however, bottom-up mobilisation of solidarity on social media to be not entirely autonomous, but rather to be responsive to the context of debate provided by main claimants in political news. Social media commenting would in this sense not unfold within a bubble, 
but rather contribute to the broader spectrum within which solidarity is debated at national and European level. Our research thus offers a glimpse at the reception site of political news, which allows us to measure opinions in the form of general attitudes expressed towards refugees as shaped by media discourse. We can further measure responsiveness to top-down contestation by political actors in the form of consenting or opposing claims raised by selected citizens on social media. And finally, we can measure voices in the form of political statements made by these citizen-users who intervened in the debate as secondary definers of the events.

\subsection{METHODS: AN IN-DEPTH ANALYSIS OF ONLINE SOLIDARITY CONTESTATION}

This study of solidarity contestation on Facebook covers the most intense time of the 'refugee crisis', with the highest number of refugees having arrived in Europe in September 2015. We selected the five most commented on Facebook posts with news content on the refugee crisis from three newspapers per country. ${ }^{1}$ For each post, 20 comments were coded (with a number of 300 comments per country divided per three newspapers). These 20 comments had to be the 20 most-liked top comments on Facebook in the form of primary statements of users and not replies to other user comments. In addition to the comments, the main posts (usually newspaper articles) were sampled and coded following the method of claims-making analysis described in Cinalli et al. (Chapter 6 in this volume). In that way, we are able in this chapter to systematically link top-down solidarity contestations by claimants in the news media in articles pasted on the Facebook pages of the respective news outlets with patterns of bottom-up mobilisation of user comments posted below these articles on Facebook.

The codebook for user commenting analysis was developed as a supplement to the codebook of claims-making used for main article coding (for details, see Chapter 6 in this volume) in order to grasp user responses to public contestations about European solidarity. This codebook was made applicable for team coding and imported into SPSS statistical analysis software. The unit of analysis was the single user comment. These comments were thematically related to the topic of European solidarity through the main news article - either in response to information given in the main article, in response to opinions expressed by political actors/journalists in the article, or as an independent statement/opinion/expression of sentiments in the general context of these debates. Replies to user comments expressed by other users/commenters were excluded, as were all comments that were not thematically related to the topic of the 'refugee crisis' in its broad sense. 
The degree to which user-commenters discussed refugees as objects of solidarity varied and was open to investigation. Usually (but not necessarily) comments had at least an identifiable issue and expressed an opinion on our object of solidarity (refugees). In user comments, such opinions were, however, often expressed in abbreviated forms and not given in the form of a full claim. For instance, the comment 'poor child' was considered as an opinion on our object of solidarity (here a refugee child). We did not code any comments that were unrelated to political opinion formation or contestation, such as comments that were part of a general conversation between users without a political focus, or comments that asked for clarification ("Can you explain this?"), for information or requests ("Send me the link!") as well as comments that simply tagged other Facebook users.

Our sample of user comments is thus constructed around user opinions that become most visible on newspapers' Facebook sites. This implies that non-discursive forms of comments, such as hate speech, remain hidden and only in very few instances enter our sample. The absence of hate speech is, however, not a sample bias, but a result of the process of mainstreaming user comments and making them visible on newspapers' Facebook sites. As such, it can be explained as a result of debate moderation by the site owners (the newspapers) and of Facebook's popularity ranking (the most popular user comments are unlikely to contain elements of hate speech). We have, of course, no information about the percentage of comments which breach netiquette or that are filtered out by the group moderators, but we would assume from existing studies that this number is low (in an internal survey, The Guardian speaks of $2 \%$ of comments that breach netiquette in the commenting sections on their own news site 2 ).

\subsection{ONLINE CONTESTATION IN THE CONTEXT OF THE 'REFUGEE CRISIS': MAIN FINDINGS}

During the month of September 2015, media claims-making in our longitudinal survey of refugee solidarity contestation peaked in all countries under investigation (see Chapter 6 in this volume). This peak is commonly explained with a surge of solidarity with refugees that followed the sharing of the image of Aylan Kurdi, a drowned Syrian toddler found at the beach in Turkey. The visual images of distant human suffering allowed for the emergence of what has been called "impromptu publics of moral spectatorship" (Mortensen and Trenz, 2016). The literature emphasises, however, the exceptional character of solidarity mobilisation. Sympathy with refugees was found to peak only for a relatively short period and only 
in some countries (Thomas et al., 2018). Social media also did not become a unified space for solidarity mobilisation, and the European space of solidarity was fragmented along national lines (Triandafyllidou, 2018).

Beyond this background, our study offers a comparative view on solidarity contestation in this peak moment of attention. Even though solidarity remained contested, the coverage of the Syrian civil war and of the human histories of war refugees created a European momentum. This focused attention on European solidarity contestations was clearly visible in the contentious dynamics of public claims-making in the news media (see Cinalli et al., Chapter 6 in this volume) and correspondingly also in the practice of user commenting on Facebook news sites.

\subsubsection{The Civicness of Citizens' Commentary on Facebook News Outlets}

Regarding our first scenario of an online civic culture, we investigate whether online news readers engage in an exchange of opinion about political news, and act as secondary definers of the debate, relating to original content and interpretation and entering into a more direct relationship with the objects of solidarity. The alternative scenario is that social media commenting practices lead to fragmentation of refugee solidarity debates. As an indicator for segmentation, we can analyse how users connect their comments to mainstream media content. We speak of fragmentation of solidarity contestation when user debates unfold independently of the news content provided by professional journalists and are unrelated to claims raised by political actors.

In order to investigate what kind of public sphere the bottom-up contestation presented to us, i.e. interdiscursive or fragmented, we found that commenting is generally responsive and often motivated as a form of engagement in public debate. We distinguish three forms of motivation: (1) to make a general contribution to the debate raised by the article, (2) to respond to a claim, and (3) to make an independent contribution to the debate outside the thematic context of the article. The second form is obviously the most interdiscursive, but the first and the third from a deliberative point of view can also be considered valid contributions to a political debate.

The responsiveness of commenters on Facebook and thus the degree to which they enter into an exchange of opinion is in this sense found to be high (Figure 7.1 ): $74.4 \%$ of all commenters responded to news content on the refugee crisis and only $25.6 \%$ of the users posted unrelated independent statements (most of them, however, still within the thematic context of the refugee crisis). Among those comments, which related directly to news content, the majority $(39.2 \%)$ responded to the general issue raised in the 


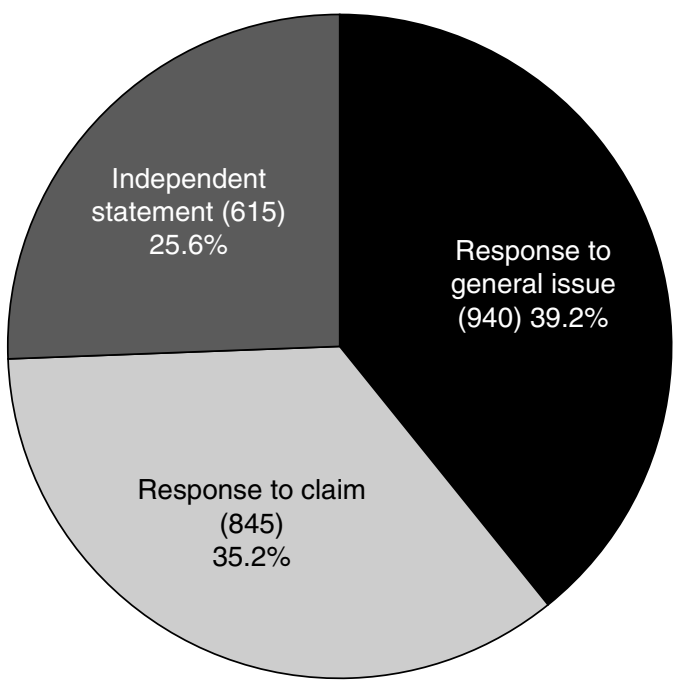

Figure 7.1 Comment type: in \% and frequency in brackets

main article, but every third comment (35.2\%) also responded to a claim raised by a claimant in the main article.

Instead of an online bubble, there was a vivid exchange of content and information between news articles and user comments. This suggests that commenters form a group of engaged citizens who wish to express their voice on highly contentious issues. In other words, these findings show that a majority of the commenters talked back to content and claimants in the media. The power of media claimants as primary definers of the debate is, in this sense, not challenged but rather confirmed by online commenting. The content and the claims raised in the news article set the context for user debates and their interpretations and expressions of opinions.

Given the reactive nature of the comment sections (Reagle, 2015: 2), their responsiveness can be assessed further by analysing how commenters, who responded to the issues or claims in the posted news article, talk back to claims. Note that the categories in Table 7.1 do not refer to commenters' tone regarding solidarity (which will be discussed at a later point) but shed light on commenters' response patterns to journalistic output. We find that the great majority of commenters $(80.1 \%)$ took sides in the sense of either affirming or opposing claims or issues in the posted news article. Among those, $47 \%$ of responsive comments were in opposition to the general issues or claims in the main article, and only $33.1 \%$ expressed support. User commenting was, in this sense, found to be more critical than affirmative. 
Table 7.1 The type of comment by position of commenter towards the issuelclaim in the posted article (frequencies in brackets) ${ }^{3}$

\begin{tabular}{lcccc}
\hline & $\begin{array}{c}\text { Negative/ } \\
\text { opposing }\end{array}$ & $\begin{array}{c}\text { Neutral/ } \\
\text { ambivalent }\end{array}$ & $\begin{array}{c}\text { Affirmative/ } \\
\text { supportive }\end{array}$ & Total \\
\hline Response to general issue & $29.6 \%$ & $10.1 \%$ & $14.3 \%$ & $54.0 \%$ \\
$\quad$ in main article & $(463)$ & $(158)$ & $(224)$ & $(845)$ \\
Response to claim raised & $17.4 \%$ & $9.8 \%$ & $18.8 \%$ & $46.0 \%$ \\
$\quad$ in main article & $(272)$ & $(154)$ & $(294)$ & $(720)$ \\
Total & $47.0 \%$ & $19.9 \%$ & $33.1 \%$ & $100 \%$ \\
& $(960)$ & $(428)$ & $(626)$ & $(1565)$ \\
\hline
\end{tabular}

Further research should probe into the direct connection between claims for and against solidarity and commenters' responses to investigate what kinds of responses pro- or anti-refugee claims in news articles trigger opposition or affirmation among commenters. Nevertheless, it is still possible to interpret commenters' positionality towards this posted journalistic output mostly as a direct reaction in the form of actively taking sides in a controversial political debate. These findings lend some support to other research on social media commenting and might further contribute to differentiating among different contexts and platforms where commenting takes place (Hille and Bakker, 2014), instead of understanding comment sections on mainstream news Facebook pages as an outlet for blatant political outrage and disillusion that ignores political discourse.

Furthermore, in order to understand what is at stake in commenters' contestation regarding solidarity with refugees and asylum seekers, we looked at the issues (or concerns) raised (see also claims-analysis, Cinalli et al. Chapter 6 in this volume). Although the limited sample size does not allow for more general observations, the online claims seem to follow the broader patterns of print claims regarding main claimants and issues to a great extent, putting state actors as claimants and issues of migration management centre stage (see Cinalli et al. in this volume). Our analysis reveals that the issue agenda of news and the agenda of topics raised for debate in online commenting largely overlapped, yet with a slightly different emphasis put by online commenters that reflects a more bottom-up dynamic of mobilisation (Figure 7.2). 37.7\% of commenters raised issues regarding migration management, which was also the most salient issue in media claims-making. Commenters put, however, comparatively less emphasis on control policies and raised a more diverse mix of issues. Bottom-up mobilisation did not, in this sense, simply mirror the political agenda of news but added to the plurality of the debate and a more profound 


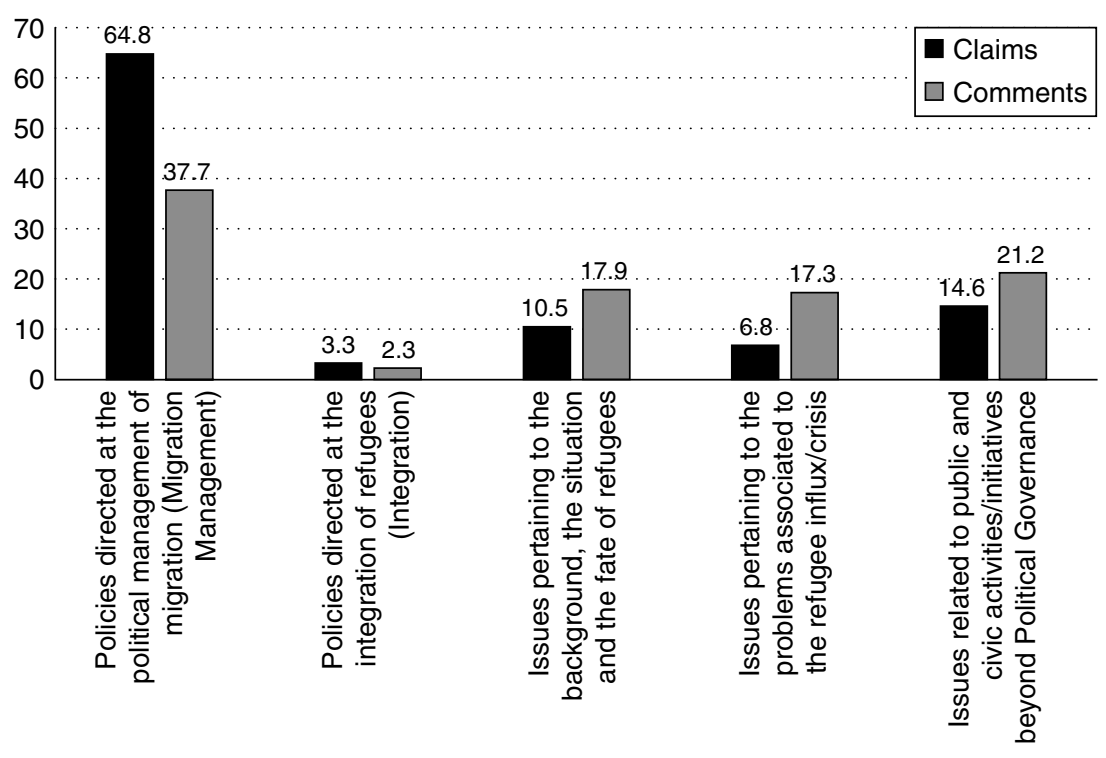

Figure 7.2 Main issues in claims and comments (\%)

understanding of issues relating to refugee solidarity by highlighting, for instance, civic initiatives $(21.2 \%)$ as well as the potential consequences of the influx (17.3\%) and personal backgrounds of refugees and asylum seekers $(17.9 \%$ ) (Table 7.2). This suggests a focus on more personal aspects regarding the 'refugee crisis' in which commenters shared their own experiences and views. In this sense, the comment sections also gave expression to bottom-up views on the 'refugee crisis', and, more precisely, offered a look into the concerns and demands of those more active citizen-users. Despite the overall congruence of issues of concern in the refugee debate from top-down and bottom-up perspectives, we find important nuances in user commenting that speak for the expression of a plurality of issues and concerns in social media, and not a narrowing down of the news agenda. The power of claims-makers as primary definers of the debate is, at least to some degree, challenged by commenters, who as secondary definers of the debate, partly replicated the issue agenda of the news media but partly also shifted its emphasis.

For our understanding of solidarity contestation across countries, it is of further interest to investigate whether commenters across countries focused on the same issues or whether attention was distributed unequally with different issues brought into focus by commenters in different countries. This is also relevant since national news-making is focused on 


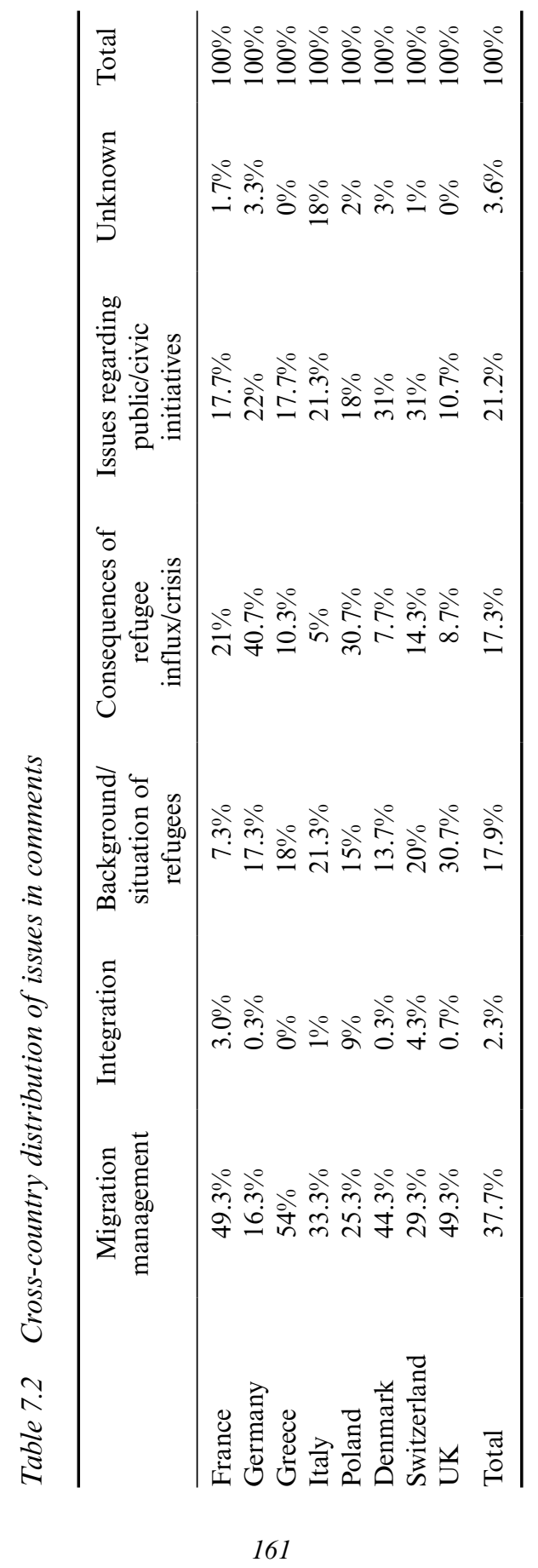


their specific national audiences (Pfetsch, 2007). However, as shown in Table 7.2, we did not find a clear pattern in the cross-country distribution of issue attention, apart from an overall congruence of the agenda, which makes us conclude that from a bottom-up perspective, the 'refugee crisis' raised similar issues of concerns in all countries under investigation. Commenters in all countries focused on the 'refugee crisis' as a management problem that required the state to regain control and adopt adequate policies. Further, there was concern regarding the general consequences of crisis and the problems created by refugees. Non-state civic activities also figured prominently, especially in Denmark and Switzerland. The background situation and the fate of refugees were also discussed to some degree, especially around the case of the drowned Syrian boy, Aylan Kurdi.

Finally, we were able to establish degrees of moral commitment of online news readers with refugee solidarity. We did so by distinguishing between comments which directly or indirectly related to refugees as an object of solidarity, and comments which did not engage in this kind of solidarity contestation (Table 7.3). The analysis shows that, across countries, the majority of commenters did indeed show engagement in solidarity contestation. Thus, commenters on the Facebook news sites on average strongly tended towards leaving comments directly related to refugees and did not shift the focus of debate contesting other unrelated issues (such as the legitimacy of domestic actors during the 'refugee crisis'). They took sides on the question regarding solidarity for refugees. These dynamics of taking sides on refugee solidarity will be analysed in further detail in the next section.

The differentiation between comments referring directly to refugees as potential recipients of solidarity and those that do not also serves another purpose. It refines our analysis of solidarity contestation regarding users'

Table 7.3 Comments relating to refugees/not relating to refugees as 'object'

\begin{tabular}{lccc}
\hline & $\begin{array}{c}\text { Refugees not the } \\
\text { object of comment }\end{array}$ & $\begin{array}{c}\text { Refugees discussed as } \\
\text { objects of solidarity }\end{array}$ & Total \\
\hline France & $8.7 \%$ & $91.3 \%$ & $100 \%$ \\
Germany & $33.0 \%$ & $67.0 \%$ & $100 \%$ \\
Greece & $8.0 \%$ & $92.0 \%$ & $100 \%$ \\
Italy & $20.3 \%$ & $79.7 \%$ & $100 \%$ \\
Poland & $20.3 \%$ & $79.7 \%$ & $100 \%$ \\
Denmark & $22.7 \%$ & $77.3 \%$ & $100 \%$ \\
Switzerland & $2.3 \%$ & $97.7 \%$ & $100 \%$ \\
UK & $13.3 \%$ & $86.7 \%$ & $100 \%$ \\
Total & $16.1 \%$ & $83.9 \%$ & $100 \%$ \\
\hline
\end{tabular}


emotional and moral expressions by enabling us to focus on the specific comments that engage in the relationship with refugees directly. In the following, we therefore only refer to the $83.9 \%$ of comments (column 3 in Table 7.3).

\subsubsection{Reactions to the Witnessing of Human Suffering}

Our comment analysis builds on this notion of a politics of pity by investigating the way emotions such as fear or pity are given political expression. We do not analyse emotions directly, but the way emotion is translated into a public statement of solidarity that takes sides. Consequently, we are focusing on moral debates in which citizens became engaged in debating whether solidarity should be granted or not (see Mortensen and Trenz, 2016). Through our combination of claims-making and reader commenting analysis, we argue that fear or pity as expressed in strong emotions in media discourse was turned into public speech, i.e. used as an element of claims-making through which responsibility was ascribed and politicians were called upon to act. The question thus is how a politics of pity interferes with a politics of fear in media discourse, what contributes to the salience of pity or fear at any particular moment of the debate, and who defines and interprets pity and fear and translates them into calls for or rejections of solidarity.

\section{Taking sides in the solidarity question}

By looking at commenters' tonality regarding refugees, we can measure degrees of polarisation of the solidarity debates. We speak of a polarisation of solidarity contestation when user comments mainly clashed with political actors who spoke in the media and expressed diametrically opposed opinions or when their opinions were, on average, more extremist on the scale of positionality.

We first analyse how far users relate to refugees. Generally, across all countries, we can see that even though the majority $(47.7 \%)$ rejects solidarity with refugees, there was a substantial minority of supportive users (31.1\%), while $21.3 \%$ remained neutral or ambivalent (Table 7.4$)$. These numbers suggest a degree of polarisation or disagreement among the commenters on the solidarity question. This, again, implies a need to develop a more differentiated understanding of online commenting sections - legacy news Facebook pages display comment sections through which users engage directly with posted journalistic output (see Table 7.1). Rather than a homogenous group displaying widespread anger towards or rejection of refugees, we do find commenters adopting a wide variety of stances towards refugees and posting a diverse range of material. Nevertheless, 
Table 7.4 Percentage tonality of claims and comments across countries

\begin{tabular}{llllllll}
\hline & \multicolumn{3}{c}{ Claims in newspapers } & & \multicolumn{3}{c}{ Comments } \\
\cline { 2 - 5 } \cline { 7 - 8 } & Anti & Neutral & Pro & & Anti & Neutral & Pro \\
\hline France & $28.5 \%$ & $24.5 \%$ & $47 \%$ & & $53.3 \%$ & $26.3 \%$ & $20.4 \%$ \\
Germany & $22.6 \%$ & $28.2 \%$ & $49.2 \%$ & & $55.2 \%$ & $21.4 \%$ & $23.4 \%$ \\
Greece & $41.5 \%$ & $17 \%$ & $41.5 \%$ & & $24.6 \%$ & $42 \%$ & $33.3 \%$ \\
Italy & $31.9 \%$ & $22.3 \%$ & $45.8 \%$ & & $27.6 \%$ & $23 \%$ & $49.4 \%$ \\
Poland & $27.2 \%$ & $29 \%$ & $43.8 \%$ & & $75.3 \%$ & $15.9 \%$ & $8.8 \%$ \\
Denmark & $39.3 \%$ & 14.5 & $46.2 \%$ & & $47.4 \%$ & $12.9 \%$ & $39.7 \%$ \\
Switzerland & $24 \%$ & $14.4 \%$ & $61.6 \%$ & & $48.8 \%$ & $16.4 \%$ & $34.8 \%$ \\
UK & $40.7 \%$ & $24.6 \%$ & $34.7 \%$ & & $52.3 \%$ & $10 \%$ & $37.7 \%$ \\
Total & $30.7 \%$ & $22.3 \%$ & $47 \%$ & & $47.7 \%$ & $21.3 \%$ & $31.1 \%$ \\
\hline
\end{tabular}

users who reject solidarity are most dominant, a finding which is important to note when considering that the claims in the posted news articles are more strongly positive towards refugees (47\%). Indeed, the distribution of negative and positive tone seems to be mirrored in reverse when comparing claims in posted news articles with comments (news claims: $30.7 \%$ negative, $22.3 \%$ neutral, $47 \%$ positive; comments: $47 \%$ negative, $21.3 \%$ neutral, $31.1 \%$ positive). This seems to suggest that comment sections serve not only the purpose of taking sides regarding a political issue, but also to take voice by being critical of top-down political discourse.

In order to understand this possible implication better, we look more closely at the average tone in the comment sections, which provides further details to the percentages in Table 7.4. As shown in Figure 7.3, the online claims in the most popular Facebook articles during September were, on average, rather positive towards refugees. ${ }^{4}$

This is interesting from the viewpoint of understanding commenters in terms of taking sides on the question of solidarity with refugees. Except for Greece and Italy, where online claims and commenters were positive, we found that commenters tended to be more negative towards refugees than claimants in the online news articles (Figure 7.4).

By looking more closely at the country differences, we find that commenters in countries with external borders that were crossed by refugees, Italy and Greece, were on average more positive towards refugees, while commenters in Germany, whose government 'welcomed' high numbers of refugees in September 2015, tended to reject refugee solidarity. Poland, with the lowest number of asylum applications $(9,490)$ in our sampling period from August 2015 to April 2016 (Eurostat, 2018), was the most negative country. 


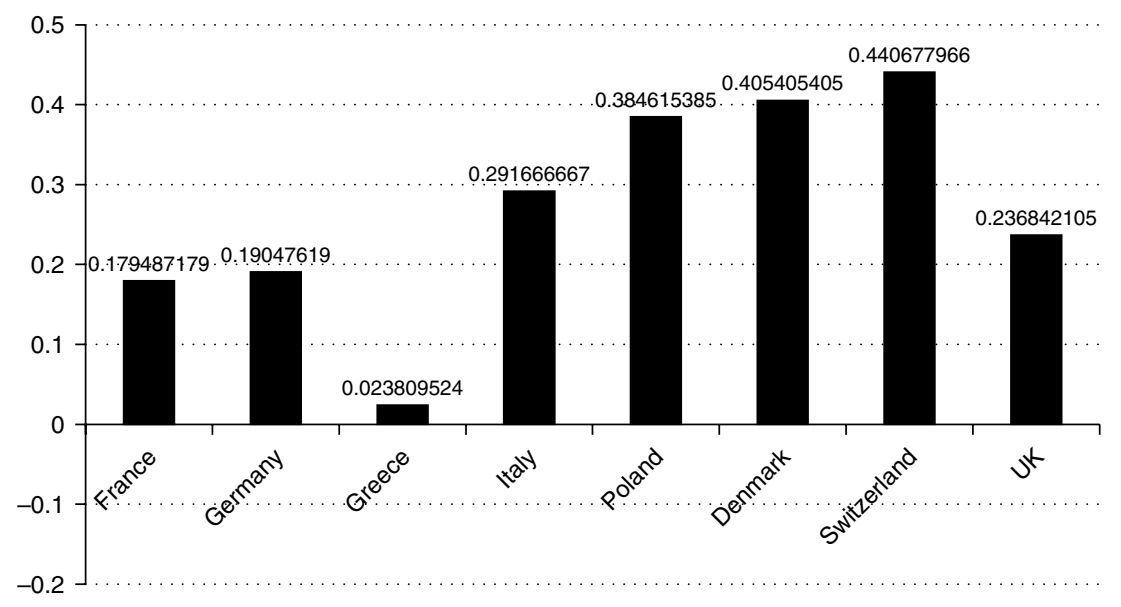

Figure 7.3 Average tonality in claims in Facebook posted news articles

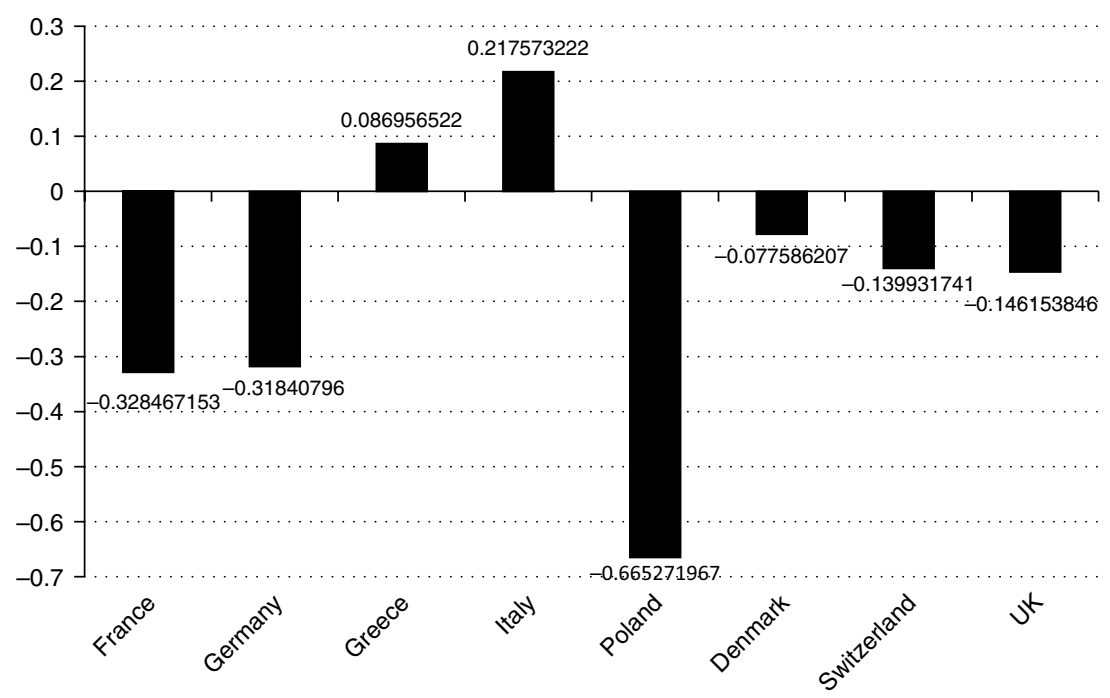

Figure 7.4 Tonality of commenters across countries

It is further noteworthy that negative and supportive commenters raised different issue agendas (Tables 7.5 and 7.6). In line with a politics of fear, the most salient issue of migration management was more strongly referred to by negative commenters (Table $7.5: 42.0 \%$ ), ${ }^{5}$ followed by issues relating to the consequences of increased migration influx to their 
Table 7.5 Issues among commenters with negative stance towards refugees ${ }^{6}$

\begin{tabular}{lcccccc}
\hline & $\begin{array}{c}\text { Migration } \\
\text { Management }\end{array}$ & Integration & $\begin{array}{c}\text { Background/ } \\
\text { situation: } \\
\text { refugees }\end{array}$ & $\begin{array}{c}\text { Consequences } \\
\text { of refugee } \\
\text { influx/crisis }\end{array}$ & $\begin{array}{c}\text { Issues } \\
\text { regarding } \\
\text { public/civic } \\
\text { initiatives }\end{array}$ & Total \\
\hline France & $61.6 \%$ & $1.4 \%$ & $2.7 \%$ & $22.6 \%$ & $11.6 \%$ & $100 \%$ \\
Germany & $20.7 \%$ & $0.0 \%$ & $4.5 \%$ & $64.9 \%$ & $9.9 \%$ & $100 \%$ \\
Greece & $57.4 \%$ & $0.0 \%$ & $4.4 \%$ & $25.0 \%$ & $13.2 \%$ & $100 \%$ \\
Italy & $43.9 \%$ & $1.5 \%$ & $9.1 \%$ & $13.6 \%$ & $21.2 \%$ & $100 \%$ \\
Poland & $19.4 \%$ & $11.7 \%$ & $16.7 \%$ & $43.3 \%$ & $7.8 \%$ & $100 \%$ \\
Denmark & $42.7 \%$ & $0.9 \%$ & $25.5 \%$ & $17.3 \%$ & $13.6 \%$ & $100 \%$ \\
Switzerland & $35.7 \%$ & $5.6 \%$ & $12.6 \%$ & $22.4 \%$ & $23.8 \%$ & $100 \%$ \\
UK & $65.4 \%$ & $0.7 \%$ & $12.5 \%$ & $16.9 \%$ & $4.4 \%$ & $100 \%$ \\
Total & $42.0 \%$ & $3.5 \%$ & $11.6 \%$ & $29.5 \%$ & $12.5 \%$ & $100 \%$ \\
\hline
\end{tabular}

Table 7.6 Issues among commenters with positive stance towards refugees ${ }^{7}$

\begin{tabular}{lcccccc}
\hline & $\begin{array}{c}\text { Migration } \\
\text { Management }\end{array}$ & Integration & $\begin{array}{c}\text { Background/ } \\
\text { situation: } \\
\text { refugees }\end{array}$ & $\begin{array}{c}\text { Consequences } \\
\text { of refugee } \\
\text { influx/crisis }\end{array}$ & $\begin{array}{c}\text { Issues } \\
\text { regarding } \\
\text { public/civic } \\
\text { initiatives }\end{array}$ & Total \\
\hline France & $41.1 \%$ & $3.6 \%$ & $8.9 \%$ & $19.6 \%$ & $26.8 \%$ & $100 \%$ \\
Germany & $6.4 \%$ & $2.1 \%$ & $53.2 \%$ & $8.5 \%$ & $29.8 \%$ & $100 \%$ \\
Greece & $16.3 \%$ & $0.0 \%$ & $52.2 \%$ & $5.4 \%$ & $26.1 \%$ & $100 \%$ \\
Italy & $17.8 \%$ & $0.8 \%$ & $47.5 \%$ & $4.2 \%$ & $29.7 \%$ & $100 \%$ \\
Poland & $23.8 \%$ & $4.8 \%$ & $23.8 \%$ & $9.5 \%$ & $38.1 \%$ & $100 \%$ \\
Denmark & $37.0 \%$ & $0.0 \%$ & $12.0 \%$ & $1.1 \%$ & $48.9 \%$ & $100 \%$ \\
Switzerland & $26.5 \%$ & $2.0 \%$ & $27.5 \%$ & $6.9 \%$ & $35.3 \%$ & $100 \%$ \\
UK & $25.5 \%$ & $1.0 \%$ & $61.2 \%$ & $0.0 \%$ & $12.2 \%$ & $100 \%$ \\
Total & $24.4 \%$ & $1.3 \%$ & $38.0 \%$ & $5.6 \%$ & $30.2 \%$ & $100 \%$ \\
\hline
\end{tabular}

countries (29.5\%). As Table 7.6 shows, positive commenters, instead, in line with a politics of pity, highlighted refugees' personal backgrounds and situations $(38.0 \%$, compared to $11.6 \%$ in negative comments), followed by a focus on civic initiatives $(30.2 \%)$. Hence, whenever the background situation or fate of the refugees was referred to (politics of pity), this increased the likelihood of a positive positioning towards refugees. If instead an emphasis was put on crisis (politics of fear), this was mostly done in the context of a negative statement towards the refugees. If governance and state policies were mentioned, this was mainly combined 
with negative attitudes towards refugees, while civic activities were related to positive statements.

Consequently, we find different issue patterns between negative and positive commenters. The generally more personal focus on the comments in comparison to claims (see Chapter 6 in this volume) might derive from the more positive commenters. This group of citizen-users might therefore relate to refugees more directly (and personally) by highlighting their backgrounds and pathways to Europe. They also referred to (often local) initiatives beyond political governance. In this way, and possibly to a higher degree than claimants in the news media, positive commenters did not dehumanise refugees. On the contrary, they focused on humanitarian issues in the 'refugee crisis'.

Summing up this section, we can conclude that Facebook commenting on mainstream newspaper sites became a site of moral commitment with questions of refugee solidarity. In this moment of heightened attention, a politics of fear was balanced by a politics of pity with a focus on the need to provide humanitarian assistance in an emergency situation. User commenting forums were not found to be (as is commonly assumed) the place for radicalisation of political opinion through the expression of xenophobia or hatred, partly because such more radical opinions were downgraded by other users and thus did not appear in our sample of most popular comments, partly because, as we must assume, they were filtered out by the moderators of the Facebook pages as a breach of netiquette. At least below the most popular posts and the respective most popular comments that were ranked highest on Facebook and likely moderated by the newspapers' web administrators, refugee solidarity was debated in a rather balanced way, with a majority rejecting refugee solidarity. However, this anti-solidarity voice did not dominate the debate and also did not systematically become disrespectful towards the opinions of others, or towards our objects of solidarity.

\section{Justifications}

Online commenting forums are not structured in a way to facilitate an exchange of arguments among users. Commenters rarely enter a dialogue with each other. Providing justifications by expressing one's opinions is therefore in no way self-evident, as opinions are often expressed in an abbreviated way by making use of more emotional language instead of rational argumentation. ${ }^{8}$ Our initial assumption has been, however, that a politics of pity and a politics of fear require citizen-users as witnesses of human suffering to translate their first emotional reactions into public speech. In line with this assumption, we found that a slight majority of 
commenters $(57.2 \%)$ justified their stances regarding solidarity towards refugees, pointing thus to discursive contestation and engagement instead of plain opinion-stating (Figure 7.5). By making such a solidarity statement, the user-commenters thus took a side and decided about the deservingness of the refugees as an object of solidarity.

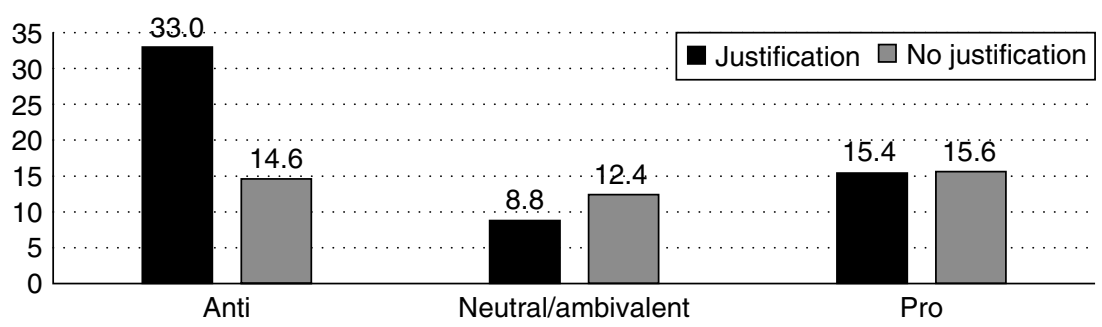

Figure 7.5 Justification versus no justification in comments with tonality towards refugees $(\%)$

By looking at the justifications of solidarity statements more specifically, we find that commenters relied on a wide spectrum of arguments. As country differences in the use of justifications were neither significant nor did they show the expected correlations (e.g. the emphasis on religion in Poland), we will in the following compare the argumentative patterns of pro- with anti-refugee commenters.

What comes to our attention first is that anti-solidarity commenters engaged to a higher degree in justificatory practices than pro-solidarity commenters (Figure 7.5). We read the lower engagement of pro-solidarity commenters in justificatory practices as a mirror of a shared perception that solidarity with people in need does not need to be justified. Humanitarian assistance and the unconditional protection of human rights are in that sense seen as a socially desirable and universal rationale guiding human behaviour and interaction.

Secondly, our findings pointed out important differences between these two groups of commenters regarding the justifications they used to underline their pro- or anti-solidarity stances (Figure 7.6). In the anti-solidarity comments with a justification against solidarity with refugees, the most frequent argument used was that national citizens should be regarded first (welfare chauvinism, 16.1\%). This was followed by references to the inappropriateness of migrants' behaviour (11.9\%). Religious reasons ranked third on average at $9.7 \%$. Comments with a positive stance towards refugees were less frequently justified (no justification found in 50.3\% compared to $30.7 \%$ in the negative comments). In particular, Greece and Italy stood out as cases in which commenters posted frequently without 


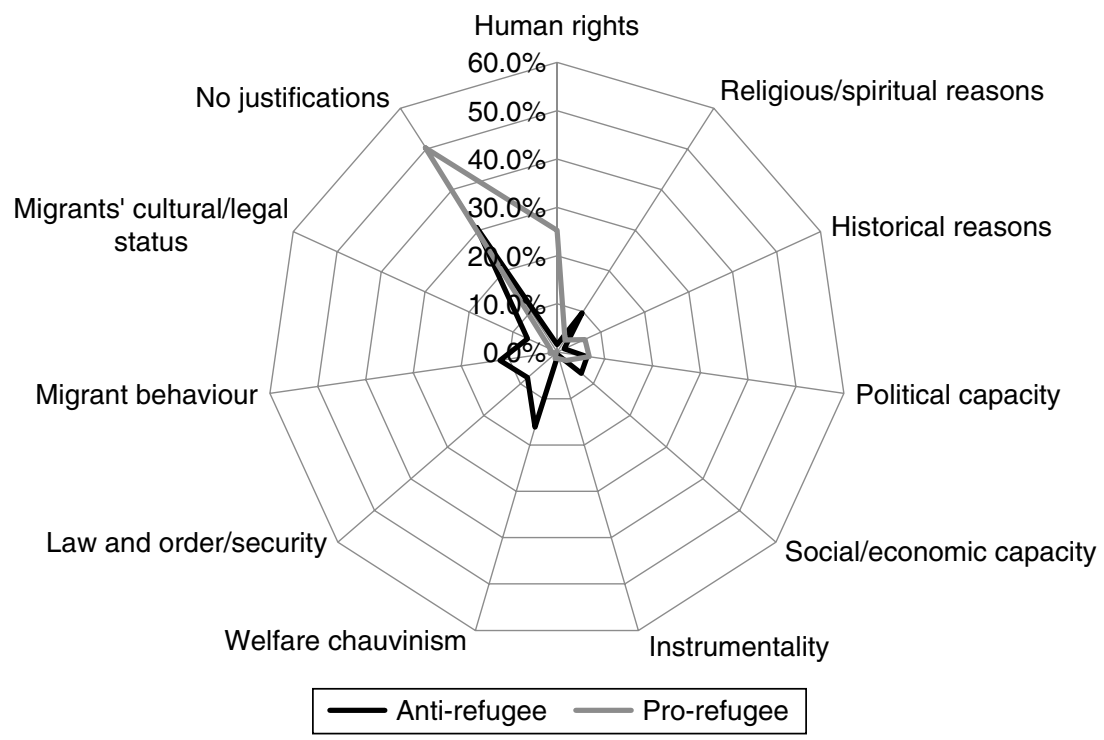

Figure 7.6 Justifications of solidarity of negative and positive comments compared

justifications (Greece $77.2 \%$ and Italy $56.9 \%$ ). These were also the two countries in which commenters were, on average, more positive towards refugees. Pro-solidarity justifications most frequently referred to human rights and broader humanitarian aspects $(25.2 \%$ of positive comments compared to only $1.6 \%$ in negative comments).

These findings further back the first scenario of an online civic sphere of solidarity contestation, especially with regard to the assumption of the building of critical capacities of online commenters. Taking sides on the question of refugee solidarity in user comments and engagement in a politics of fear or politics of pity creates a justification requirement. Following the pattern of social desirability, solidarity towards people in need of assistance is a mandatory response on social media news sites. The choice to reject solidarity towards those people in need, therefore, requires the proponent of a claim to engage in an explicit justification (Chouliaraki, 2013). The quite substantial presence of commenters with positive views on refugees and a positive attitude (often termed 'do-gooders' by negative commenters), further challenges the negative majority to engage in the formulation of arguments for their antisolidarity choices. In other words, commenters feel urged to back their anti-solidarity opinions with arguments, i.e. explain why they are against 
refugees. Pro-solidarity contestants instead speak in the name of a higher morality and of absolute values.

Finally, we need to discuss the idea of whether users' taking sides and witnessing human suffering translates into more open forms of user engagement and participation. ${ }^{9}$ People who make use of online media channels when it comes to political affairs are, therefore, not to be regarded as representative of the whole population, but show a political interest, are probably younger and better educated and, as such, may be more likely to be politically active (see e.g. Vissers and Stolle, 2014; Mellon and Prosser, 2017), and more critical of how solidarity politics are practised in the EU (Brändle and Eisele, 2019). More specifically, we ask whether commenters in this particular debate constituted a politicised group of citizens that mobilise around solidarity contestation - either by showing activism in terms of readiness for political mobilisation or extremism in terms of more radical opinion (as compared to the claimsmakers in the media).

Contrary to our assumption of bottom-up mobilisation in support of a politics of fear or a politics of pity, our analysis does not reveal high levels of political activism in online commenting. Among the comments just slightly more than a quarter called for action $(27.4 \%)$, while in nearly three quarters of them (72.6\%), no calls for action could be identified. Although it is difficult to say whether a quarter of comments calling for action is truly a small percentage (in the absence of comparative data with comments in other fields), we find that refugee debates in all countries were mainly fought verbally, and much less frequently linked to calls for protest or solidarity action. In addition, these calls for action mainly addressed the government as a legislator and did not try to mobilise fellow citizens. This is also in line with our claims-making analysis, which revealed a rather low salience of direct solidarity action as an element of news coverage. Among those with calls for action, as shown in Figure 7.7, direct action, such as protest and calls for solidarity, was even less visible in user comments than in the political news.

Even in countries like Germany, proud of its welcoming culture, the acts of welcoming were not made visible in the media. The commenting section on Facebook is not, in this sense, the place where political protest is mobilised, nor is it the place where solidarity action in the form of charity or humanitarian assistance is given support. On the contrary, the responsibility to take sides is delegated and the government/state is called upon to 'do something about it'. 


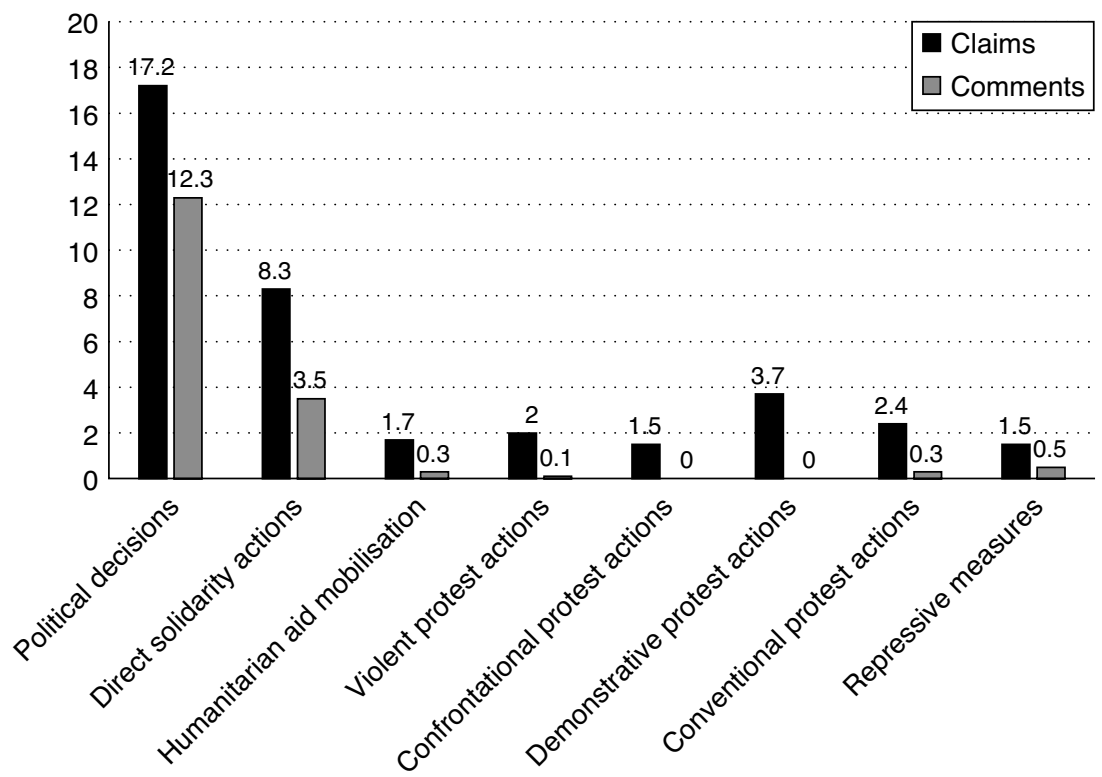

Figure 7.7 Form of call for action in printed claims and comments (\%)

\subsection{CONCLUSION: AN INTEGRATED SPHERE OF ONLINE SOLIDARITY CONTESTATION}

The Facebook comment sections of mainstream newspaper sites offered an opportunity for focused debates about the 'refugee crisis'. Our comparative view on bottom-up solidarity contestation at the height of the so called 'refugee crisis' shows how citizen-users on Facebook all over Europe took the opportunity to take voice on an issue of shared concern. This voice was raised in the commenting sections of mainstream newspapers' public Facebook sites, and was informed and motivated by the witnessing of a humanitarian disaster and human suffering but also, and more dominantly, by diffuse feelings of fear in light of a seemingly uncontrolled influx of refugees. We found elements of a politics of fear and a politics of pity, which translated emotions into public speech in the form of political statements that took sides and positioned themselves on the question of whether solidarity with refugees should be granted or not.

These dynamics of bottom-up solidarity contestation are first of all found to be closely related to the dominant public and political discourse in a particular national country context. As such, the contentiousness around issues of (trans)national solidarity found in other chapters in this 
volume in relation to civil society and political mobilisation is reflected here in the media behaviour of citizens. This confirms the centrality of the media public sphere (both online and offline) for solidarity mobilisation functioning in a way to balance different positions and exchange arguments about the deservingness of particular target groups of solidarity (Trenz, 2019). Our findings particularly offer fresh insights on the role of social media commenting, which might not necessarily be a place for an undifferentiated, angry user community, as is often assumed (the online bubble) (Flaxman et al., 2016). Looking at public Facebook sites of mainstream newspapers, we found a strong linkage between online news and online commenting. This points to an integrated public sphere of solidarity contestation, where primary definers (claims-makers such as politicians, stakeholders or intellectuals) in the news media set the agenda and the main frames for secondary definers of the debate in terms of-social media users' responses. In this debate by secondary definers, a plurality of issues is raised dominantly relating to security concerns, but highlighting also a plethora of other issues, such as the welfare state and aspects of civil society, or the destiny of refugees, their living conditions and personal stories of flight. Bottom-up solidarity contestation is most often verbally fought, and social media are not used for targeted political mobilisation in the sense of direct calls for protests or acts of solidarity.

Looking more closely at the dynamics of taking sides, on the question of refugee solidarity, we find that opinions expressed by commenters were overall more negative than the opinions expressed by claims-makers in the news media, which were still balanced in most countries (except Poland) by a substantial minority, backing solidarity with refugees. In two countries (Italy and Greece), a positive view even prevailed over hostility. The comment sections of news sites on Facebook were, however, not used for the expression of political extremism, of xenophobia or of hate towards foreigners. Nor do we find the online voice to be particularly polarised. Again, it is likely that news sites moderate their Facebook pages as well as take preventive measures by selecting less controversial news content to be posted on Facebook.

Online users in all countries systematically related to the positions of claims-makers in the media and tended to be critical towards them, not affirmative. They did not, however, take fundamentally opposed views to the ones expressed by political representatives. In equal terms, their views expressed towards the refugees as our object of solidarity were balanced and they did not seek polarisation or direct confrontation. Three deviating countries - Italy, Greece and Denmark - are interesting, as the citizen voice here was, on average, more positive towards refugees than the voice of claims raised in the print news media. This is a significant finding, 
which makes us aware how solidarity contestation towards refugees and the domestic contestation of the national political actors are interrelated. A negative view on national government can motivate a positive expression of solidarity towards refugees. In Germany and France, instead, where the governmental position towards refugee solidarity was positive during the month of September, the larger share of negative positioning of citizenusers towards refugee solidarity might also be explained as an implicit or explicit critique of national government.

The analysis of justifications used to back or reject refugee solidarity reveals an interesting dynamic of how solidarity was made conditional in public debates. Taking sides on the question of refugee solidarity generates a requirement to enter a justification of one's position. These requirements for justification are, however, spelled out differently depending on the pro- or anti-solidarity position one wishes to defend. While pro-solidarity commenters often relied on an unconditional form of justification such as the higher morality of human rights and absolute values, the anti-solidarity commenters most commonly defended a notion of conditional solidarity. This required them to spell out the conditions under which solidarity should apply or be withdrawn. The anti-solidarity voice in all countries generated, therefore, a higher amount of justifications than those comments that called for solidarity with refugees.

Coming back to the specific situation of humanitarian emergency in September and the controversial decisions by the German government to open its borders to refugees, we might ask to what extent our purposive sample of the most popular comments on news sites mirrors the switch of public opinions during that time from hostile to more supportive attitudes of the population towards refugees (Ditlmann et al., 2016). The so called 'welcoming culture' was more reflected in news claims-making, where every country's positivity peaked in the early months of our entire sampling period. Instead of unconditionally supporting the so-called 'welcoming culture', social media users, especially in Germany, remained more distanced and critical of the decision to open the borders to refugees. They thus displayed an attitude of critical scepticism indicating already that the solidarity momentum of September 2015 would remain shortlived and exceptional, in line with other research pointing to the trend of online users engaged in EU political affairs being more critical (Brändle and Eisele, 2019).

Our findings point in this sense to a much more complex picture of solidarity contestation than expected. Instead of a clear-cut divide between cosmopolitans in support of humanitarian solidarity towards refugees, and communitarians in support of nationally exclusive notions of solidarity, we find shifting agendas and discourses. We also do not find 
an alliance between anti-refugee positions and anti-European positions; on the contrary, anti-solidarity claims were often raised in the name of Europe, and Europe is also seen by citizens in its role as a guarantor of security and exclusive solidarity. As there was a general responsiveness towards both issues and general claims raised in the news, the online user debate was mainly a general replication of the patterns of political debates found in the claims-making analysis, and not a segmented debate that followed its own logic, detached from the political mainstream. Overall, the main argument of this volume about the fragility of solidarity contestation across Europe is powerfully confirmed by this investigation of the social media sphere, where even at this exceptional moment of heightened attention towards humanitarian needs of refugees in September 2015, citizens displayed rather different attitudes across arenas and countries and on the whole remained rather critical and distanced with regard to the solidarity claims raised by political elites in mainstream media. Social media therefore remain fragile and contested arenas of solidarity. The solidarity momentum of September 2015 woke a short-lived compassion for refugees, but as evidenced by the rapid shifts of opinion in subsequent months, it was difficult to translate this into an enduring solidarity moment (Vollmer and Karakayali, 2017).

\section{NOTES}

1. The country cases and online newspapers selected are identical with the newspapers selected for our claims-making (France: Le Monde, Le Figaro and Le Parisien; Germany: Süddeutsche Zeitung, Frankfurter Allgemeine Zeitung and Spiegel instead of Bild; Greece: Proto Thema, Ta Nea and Kathimerini; Italy: La Repubblica, Corriere della Sera and Il Giornale instead of Libero Quotidiano; Poland: Gazeta Wyborcza, Rzeczpospolita and Fakt; Denmark: Politiken, Jyllandsposten and BT; UK: The Guardian, The Telegraph and The Express; Switzerland: Matin, Le Temps, Neue Zürcher Zeitung, Tages Anzeiger and Blick instead of La Regione - five newspapers here due to language specifities).

2. See https://www.theguardian.com/technology/2016/apr/12/the-dark-side-of-guardian-co mments.

3. Independent statements are subtracted from the total number of comments.

4. Note, the tonality measures do not lend themselves to further interpretation and should be taken with a pinch of salt since the actual difference between countries are low decimals and the claims sample of posted news articles in this chapter is not representative but selected after contestation (see p. 155).

5. Similar for neutral or ambivalent commenters.

6. Displayed without category 'unknown', which amounts to $0.9 \%$ in total; Italy $10.6 \%$ and Poland 1.1\%.

7. Displayed without category 'unknown', which amounts to $0.5 \%$ in total; Switzerland $2 \%$ and Denmark $1.1 \%$.

8. See Chouliaraki and Stolic (2017) and Triandafyllidou (2018) for interpretative approaches towards the refugee crisis as an event that triggered particular emotions.

9. A direct link between online and offline participation cannot be measured with these data. 


\section{REFERENCES}

Boltanski, L. (1999). Distant Suffering: Morality, Media and Politics. Cambridge: Cambridge University Press.

Brändle, V. K. and Eisele, O. (2019). Sharing is caring? Exploring the relationship between preferences for online participation and support for solidarity between EU member states. American Behavioral Scientist, 63(4): 523-37.

Chouliaraki, L. (2013). The Ironic Spectator: Solidarity in the Age of PostHumanitarianism. Cambridge: Polity.

Chouliaraki, L. and Stolic, T. (2017). Rethinking media responsibility in the refugee 'crisis': a visual typology of European news. Media, Culture \& Society, 39(8): 1162-77.

Cinalli, M. and Giugni, M. (2013). Public discourses about Muslims and Islam in Europe. Ethnicities, 13: 131-46.

Cinalli, M. and Giugni, M. (2016). Citizens' responses to the European economic crisis in the public domain. Politics and Policy, 44: 388-99.

Coleman, S. (2013). How Voters Feel. New York: Cambridge University Press.

Dahlgren, P. (2013). The Political Web: Media, Participation and Alternative Democracy. Basingstoke: Palgrave Macmillan.

Della Porta, D. (2018). Solidarity Mobilizations in the 'Refugee Crisis': Contentious Moves. Basingstoke: Palgrave Macmillan.

Ditlmann, R., Koopmans, R., Michalowski, I., Rink, A. and Veit, S. (2016). Verfolgung vor Armut ausschlaggebend für die Offenheit der Deutschen ist der Fluchtgrund. WZB Mitteilungen, 151, March 2016 (https://www.wzb.eu/sites/ default/files/publikationen/wzb_mitteilungen/veits24-27151-webpdf-2.pdf).

Eurostat (2018). Asylum and first-time asylum applicants by citizenship, age and sex Monthly data (rounded) [migr_asyappctzm], extracted 22.03.2018 (https:// ec.europa.eu/eurostat/web/products-datasets/product?code=migr_asyappctzm).

Flaxman, S., Goel, S. and Rao, J. (2016). Filter bubbles, echo chambers, and online news consumption. Public Opinion Quarterly, 80: 298-320.

Freeman, G. P. (1995). Modes of immigration politics in liberal democratic states. International Migration Review, 29(4): 881-902.

Freeman, G. P. (1998). The decline of sovereignty? Politics and immigration restriction in liberal states. In C. Joppke (ed.), Challenge to the Nation State: Immigration in Western Europe and the United States. Oxford: Oxford University Press, pp. 86-108.

Galpin, C. and Trenz, H. J. (2019). Participatory populism: online discussion forums on mainstream news sites during the 2014 European parliament election. Journalism Practice, 13(7): 781-98.

Georgiou, M. and Zaborowski, R. (2017). Council of Europe Report: Media Coverage of the "Refugee Crisis": A Cross-European Perspective. DG1(2017)03 (https://rm.coe.int/1680706b00).

Gerbaudo, P. (2014). Populism 2.0: social media activism, the generic Internet user and interactive direct democracy. In D. Trottier and C. Fuchs (eds), Social Media, Politics and the State: Protests, Revolutions, Riots, Crime and Policing in the Age of Facebook, Twitter and YouTube. New York: Taylor and Francis, pp. 67-87.

Gerhards, J. and Schafer, M. S. (2010). Is the internet a better public sphere? Comparing old and new media in the US and Germany. New Media \& Society, 12(1): 143-60. 
Givskov, C. and Trenz, H. J. (2014). Civic engagement through mainstream online newspapers: possibilities and shortcomings. MedieKultur, 30(566): 44-60.

Hille, S. and Bakker, P. (2014). Engaging the social news user. Journalism Practice, 8(5): 563-72.

Krämer, B. (2017). Populist online practices: the function of the Internet in rightwing populism. Information, Communication \& Society, 20(9): 1293-1309.

Mellon, J. and Prossor, C. (2017). Twitter and Facebook are not representative of the general population: political attitudes and demographics of British social media users. Research \& Politics, July-September 2017: 1-9.

Michailidou, A., Trenz, H. J. and De Wilde, P. (2014). The Internet and European Integration. Pro- and Anti-EU Debates in Online News Media. Opladen: Barbara Budrich Publisher.

Moffitt, B. (2016). The Global Rise of Populism: Performance, Political Style, and Representation. Stanford. CA: Stanford University Press.

Mortensen, M. and Trenz, H. J. (2016). Media morality and visual icons in the age of social media: Alan Kurdi and the emergence of an impromptu public of moral spectatorship. Javnost - The Public, 23(4): 343-62.

Pfetsch, B. (2007). National media in Europeanized public sphere: the openness and support of the press for European integration. In C. de Vreese and H. Schmitt (eds), A European Public Sphere: How Much Of It Do We Have and How Much Do We Need? Connex Report Series No. 2, pp. 401-25.

Rasmussen, T. (2014). Internet and the political public sphere. Sociology Compass, 8(12): 1315-29.

Rauchfleisch, A. and Kovic, M. (2016). The Internet and generalized functions of the public sphere: transformative potentials from a comparative perspective. Social Media + Society, 2(2): 1-15.

Reagle, J. M. (2015). Reading the Comments. Cambridge, MA: MIT Press.

Silverstone, R. (2006). Media and Morality: On the Rise of the Mediapolis. Oxford: Wiley.

Sunstein, C. R. (2009). Going to Extremes: How Like Minds Unite and Divide. Oxford: Oxford University Press.

Thomas, E. F., Cary, N., Smith, L. G., Spears, R. and McGarty, C. (2018). The role of social media in shaping solidarity and compassion fade: how the death of a child turned apathy into action but distress took it away. New Media \& Society, 20(10): 3778-98.

Trenz, H. J. (2019). New opportunities for European solidarity mobilization: the role of the media. In H. Krunke, I. Manners and H. Petersen (eds), Cross-Border Solidarity - Concept, Challenges and Opportunities. Cambridge: Cambridge University Press.

Triandafyllidou, A. (2018). A "refugee crisis" unfolding: "real" events and their interpretation in media and political debates. Journal of Immigrant \& Refugee Studies, 16(1): 1-19.

Visser, S. and Stolle, D. (2014). The Internet and new modes of political participation: online versus offline participation. Information, Communication \& Society, 17(8): 937-55.

Vollmer, B. and Karakayali, S. (2017). The volatility of the discourse on refugees in Germany. Journal of Immigrant \& Refugee Studies, 16(1-2): 118-39.

Wodak, R. (2015). The Politics of Fear: What Right-Wing Populist Discourses Mean. Thousand Oaks, CA: Sage. 